\title{
Do physical diagnostic tests accurately detect meniscal tears?
}

\author{
Th. Karachalios $\cdot$ M. Hantes $\cdot$ E. Zintzaras
}

Received: 27 October 2009/Accepted: 1 February 2011/Published online: 16 March 2011

(C) The Author(s) 2011. This article is published with open access at Springerlink.com

\section{Dear Editors,}

The recently published paper by Konan et al. [4] explored the validity of the currently available physical diagnostic tests for detecting meniscal tears. Among the investigated tests was the Thessaly test developed by Karachalios et al. [3]. Konan et al. [4] claim that the Thessaly test is not accurate in the detection of meniscal tears because of low diagnostic accuracy (for medial meniscus at $20^{\circ}$ of flexion, the sensitivity was $59 \%$ with a specificity $67 \%$ ).

However, the study by Konan et al. [4] has a completely different design from the study by Karachalios et al. [3]. In particular, the study by Konan et al. [4] was a cohort study, surprisingly without a control group [1], consisted of 109 patients with a differential diagnosis of meniscal tears from history and MRI evaluation. In this cohort, only 12 patients were found free of meniscal tears. Thus, the design of this study is unbalanced and the possibility of selection bias [1,2, 5] in the control population cannot be excluded. Furthermore, Karachalios et al. [3] have clearly stated that the diagnostic tests were evaluated in recent knee injuries. In contrast, this issue has not been introduced into the design of the study or discussed by Konan et al. [4].

Th. Karachalios $(\bowtie) \cdot$ M. Hantes

Department of Orthopaedic Surgery, Faculty of Medicine,

School of Health Sciences, University of Thessalia,

Thessaly, Greece

e-mail: kar@med.uth.gr

E. Zintzaras

Department of Biomathematics, University of Thessaly School

of Medicine, Larissa, Greece

E. Zintzaras

Center for Clinical Evidence Synthesis, The Institute for Clinical Research and Health Policy Studies, Tufts University School of Medicine, Boston, MA, USA
It has to be stressed that the study by Karachalios et al. [3] selected two independent groups, as it is appropriate [1] to test the diagnostic accuracy of Thessaly test: one group of 213 symptomatic patients and one group of 197 healthy controls. The control group was chosen in order to be similar in demographic characteristics and knee side to the disease group. Such a design ensures there is no bias in the testing of diagnostic accuracy and follows the appropriate methodology for assessing diagnostic tests $[1,2,5]$.

The study by Konan et al. [4] was extremely small (97 meniscus patients and 12 controls) relative to the size of the study by Karachalios et al. [3] (213 meniscus patients and 197 controls). Thus, the statistical power of the Thessaly test in Konan et al. [4] study was only $22 \%$, as estimated by the sensitivity and the specificity ( 89 and $97 \%$, respectively) of the Thessaly test in detecting medial meniscus tears at $20^{\circ}$ of flexion, found by Karachalios et al. [3] for the given size of their sample.

In conclusion, the study by Konan et al. [4] cannot be considered as a validation study of the Thessaly test since its study design settings are inappropriate [1] and very different from the original Thessaly test design, and most worryingly, its sample size was extremely small.

Open Access This article is distributed under the terms of the Creative Commons Attribution Noncommercial License which permits any noncommercial use, distribution, and reproduction in any medium, provided the original author(s) and source are credited.

\section{References}

1. Altman DG (1993) Diagnostic tests. In: Altman DG (ed) Practical statistics for medical research. Chapman \& Hall, London, pp 409-419

2. Jaeschke R, Guyatt GH, Sackett DL (1994) Users' guides to the medical literature. III. How to use an article about a diagnostic test. 
B. What are the results and will they help me in caring for my patients? The evidence-based medicine working group. JAMA 2(271):703-707

3. Karachalios T, Hantes M, Zibis AH, Zachos V, Karantanas AH, Malizos KN (2005) Diagnostic accuracy of a new clinical test (the Thessaly test) for early detection of meniscal tears. J Bone Joint Surg 87A:955-962
4. Konan S, Rayan F, Haddad FS (2009) Do physical diagnostic tests accurately detect meniscal tears? Knee Surg Sports Traumatol Arthrosc 17:806-811

5. Zintzaras E, Germenis AE (2006) Performance of antibodies against tissue transglutaminase for the diagnosis of celiac disease: meta-analysis. Clin Vaccine Immunol 13:187-192 